\title{
ENSÁIOS BIBLIOGRÁFICOS
}

\author{
O Neolítico e o Bronze Antigo no Egeu
}

Haiganuch Sarian

Museu de Arqueologia e Etnologia - USP

TREUIL, René. Le Néolithique et le Bronze Ancien Egéens. Les problèmes stratigraphiques et chronologiques, les techniques, les hommes. Bibliothèque des Ecoles Françaises d'Athènes et de Rome, fascicule 248. Paris, Diffusion De Boccard, 1983, XX -542 pp. 268 fig., 7 pranchas.

Por mais que se tenha questionado a pertinência e a validez das volumosas teses de Doctorat d'État francesas, a ponto de recorrer-se bem recentemente a uma reforma universitária que muito as modifica, basta uma consulta à importante série publicada por dois grandes institutos de Arqueologia - as Écoles Françaises d'Athènes et de Rome, para se convencer de que relevantes contribuições no campo da Antiguidade vieram justamente dessas longas e exaustivas pesquisas. A obra em apreço de René Treuil, professor da Université cie Paris I, não só confirma essa nossa opinião, como também vai muito além, revelando que ao rigor de uma rara erudição, invejável e, sem dúvida nenhuma, absolutamente necessária nessa área de estudos, manifesta uma firmeza teórica e metodológica exemplar, orientando-se assim, com inteligência, reflexão e força crítica, para resultados dos mais significativos no conhecimento da proto-história do mundo egeano.

A definição do tema, seus objetivos e métodos, são apresentados na Introduction (pp. 1-6). O ponto de partida para a pesquisa foi, a começar 
pelo estudo da passagem do Neolítico Recente para o Bronze Antigo nas regiões do Egeu, "verificar, ou infirmar, a teoria comumente admitida, que vê na passagem para a Idade do Bronze a consequiência principal de uma migração vinda da Anatólia e, daí, da coexistência mais ou menos prolongada de populações antigas e de populações novas” (p. 1). Essa teoria tem sido amplamente aceita, e o Autor cita apenas algumas obras que trataram do assunto, os estudos de Delvoye, Demargne e Renfrew (1). Essa primeira questão levaria forçosamente a uma outra verificação: a civilização vinda da Anatólia e instalada no Egeu teria, através de influências ou migrações, atingido toda a Europa (2).

Com essas premissas, que foram depois secundadas por outros temas que se revelaram igualmente importantes, $\mathrm{R}$. Treuil dedicou-se a uma ampla pesquisa que originou um panorama das civilizações egeanas do início do Neolítico até o final do Bronze Antigo. Certamente, essa vasta documentação arqueológica apresentava inúmeras dificuldades que foram dominadas com maestria e que exigiram tempo: tal documentação referia-se a materiais de escavações efetuadas anteriormente, numerosas e extensas, divididas e dispersas nos territórios de cinco países atuais (Turquia, Grécia, Albânia, Iugoslávia e Bulgária acrescentando-se comparações obrigatórias com Chipre e Oriente Próximo, Romênia, União Soviética, Hungria e Tchecoslováquia). O volume dos dados disponíveis exigiu do Autor mais de uma reflexão, como a que recai sobre a maneira de tratar e de expor a documentação: "o volume e a heterogeneidade dos materiais acumulados, a fraqueza dos conhecimentos reais, tudo sugeria acentuar, no momento presente, menos os trabalhos analíticos que uma pesquisa sintética. Para isso, era preciso integrar a massa dos materiais brutos, tal como haviam sido publicados, porém renunciar a explorar todos os que permaneceram inéditos: essa tarefa ultrapassava as possibilidades de um indivíduo (...) Portanto, tive a preocupação constante de garantir essa etapa sintética” (p. 3). Para isso, foi necessário rassembler, critiquer, classer, interpréter (pp. 3-4), multiplicando as referências a vestígios arqueológicos, à bibliografia, mas com uma perspectiva histórica e etnológica na qual se manifestam inspirações confessas de, por um lado, A. Leroi-Gourhan (3) e P.

(1) - Delvoye, Chr. "Remarques sur la seconde civilisation néolithique du continent grec et des îles avoisinantes", Bulletin de Correspondence Hellénique 73, 1949, pp. 29-123; Demargne, P. in Glotz, G. La civilisation egeenne, Paris, 1952, p. 499; Renfrew, C. The Emergence of Civilisation, Londres, 1972, pp. 56-60.

(2) - Entre outros, Childe, G. L'Europe préhistorique, Paris, 1962, prefácio e cap. 7. O célcbre postulado "ex Oriente lux" que dominou e ainda domina boa parte dos estudos sobre o mundo egeano antigo é citado pelo Autor de modo pertinente e sua negação, como se verá mais adiante, constitui uma das grandes conclusôes do livro em questão.

(3) - L'honme et la matière (2.e édition), Paris, 1943; Milieu et techniques (2.e édition), Paris, 1945; Les religions de la prehistoire (Paléolithique), Paris, 1964 
Ucko (4) e, em escala menor, Marc Bloch (5). Com relação aos dois primeiros vale a pena citar o seguinte (p. 6): "Com efeito, foi aí que encontrei os procedimentos mais convincentes, as reflexões mais fecundas e, sobretudo, os exemplos mais estimulantes".

Além dessa introdução que acabamos de resumir, o livro constitui-se de três grandes partes: 1 - Le passage du Néolithique Récent au Bronze Ancien: les problémes stratigraphiques et chronologiques (pp. 9-140); 2 - Les techniques (pp. 143-342); 3 - Les hommes (pp. 346-514). Essas três partes se dividem em capítulos e sub-capítulos e terminam com conclusões parciais. Uma conclusão geral (pp. 515-519) encerra o livro, completado com um índice dos sítios arqueológicos, um índice dos assuntos, uma tábua das ilustrações constituídas de 7 mapas, 268 figuras desenhadas e 7 pranchas fotográficas, todas elas acompanhadas de suas fontes. Finalmente, deve-se ressaltar também uma riquíssima bibliografia (pp. XI-XIX) limitada aos artigos e obras mais importantes, uma vez que muitos títulos são citados com suas referências nas notas; uma lista de abreviações (pp. IX-X) ressalta 58 periódicos, dos quais se distinguem títulos pouco divulgados em nosso meio como as revistas da Grécia, da Turquia e dos países de leste.

A Primeira Parte, substanciosa e muito bem documentada, divide-se em dois longos estudos sobre estratigrafia e datações. No tocante aos problemas estratigráficos, duas questões foram apontadas, as quais receberão respostas após acurada observação: 1) a coexistência, em certas camadas, das cerâmicas atribuíveis ao Neolítico Recente com as do Bronze Antigo, uma vez que alguns arqueólogos emitiram a hipótese de que essa coexistência comprovava a comunhão de duas civilizações diferentes ou pelo menos a existência de uma fase de transição entre o Neolítico Recente (6) e o Bronze Antigo. Essa posição resultou das observações feitas por Blegen em Gonia, Holmberg em Asea e Weinberg em Corinto (7) e foi desenvolvida por Heurtley, Matz e sobretudo Weinberg (p. 9) (8). Outros

(4) - "The Interpretation of Prehistoric Anthropomorphic Figurines", Journal of the Royal Anthropological Institute 92, 1962, pp. 38-54; Anthropomorphic Figurines of Predynastic Egypt and Neolithic Crete, Londres, 1968; "Ethnography and archaelogical interpretation of funerary remains", World Archaeology 1, 19691970, pp. 262-280.

(5) - Apologie pour l'histoire ou métier de l'historien, Paris, 1941.

(6) - R. Treuil adota e defende a terminologia empregada na Grécia, Neolíitco Recente, em lugar de Calcolítico e Eneolítico, em voga na bibliografia referente ao Oriente Próximo e aos Bálcãs. A argumentaão está nas páginas 2-3 e 517 .

(7) - Blegen, C., "Gonia", Metropolitan Museum Studies 3, 1930-1931, p. 55-80; Holmberg, E., The Swedish Excavations at Asea in Arcadia, Lund-Leipzig, 1944; Weinberg, S. "Remains from Prehistoric Corinth", Hesperia 6, 1937, p. 492.

(8) - Heurtley, W., Prehistoric Macedonia, Cambridge, 1939, pp. 126-127; Matz, Fr., "Zur ägaischen Chronologie der frühen Bronzezeit", Historia 1, 1950, p. 
arqueólogos, entretanto, baseando-se nos casos em que essa coexistência não se verificava, continuaram a considerar o Neolítico Recente e o Bronze Antigo como dois períodos distintos e sucessivos: Milojcic, Schachermeyr, Theocharis e Caskey (p. 9) (9).

A segunda questão (p. 10) é muito mais importante e depende da posição cronológica relativa que se atribui à civilização (10) de Vinca-Turdas e de Tróia I: existe uma cronologia baixa ligando a civilização de Vinca à de Tróia I através de analogias observadas sobretudo nas formas e na decoração da cerâmica e essas analogias seriam a prova de um sincronismo que levaria a admitir que a Europa estaria ainda no Neolítico enquanto as regiões egeanas já conheciam a Idade do Bronze. Essa posição foi tomada independentemente de qualquer consideração estratigráfica e a bibliografia sobre ela é variada vindo desde Childe até o presente momento (11).

Esse sincronismo tem sido constestado justamente em conseqüência de rigorosas observações estratigráficas, daí a importância que R. Treuil dá ao seu estudo sistemático nas regiões egeanas. Arqueólogos como Georgiev, Deshayes e Renfrew (p. 10) (12), defendem a opinião segundo a qual a civilização de Vinca-Turdas precede a civilização de Tróia I: "as analogias são consideradas como simples convergências e o intervalo entre Vinca-Turdas e Tróia I é ocupado, além disso, por fases de duração relativamente longa, em particular aquelas que correspondem às civilizações ide Vinca-Plocnik e de Gumelnita. Para os adeptos dessa cronologia de-

190; Weinberg, S., "Aegean Chronology: Neolithic Period and Early Bronze Age", American Journal of Archaeology 51, 1947, pp. 171-174.

(9) - Milojcic, VI, "Zur Chronologie der jüngeren Steinzeit Griechenlands", Jahrbuch des Deutschen Archäologischen Instituts 65-66, 1950-1951 pp. 1-90; Schachermeyr, Fr., "Die Abfolge der neolithischen Kulturen in Griechenland" in Geras Antoniou Keramopoullou, pp. 97-102; Theocharis, D., "Nea Makri, eine grosse neolithische Siedlung in der Nähe von Marathon", Mitteilungen des Deutschen Archäologischen Instituts. Athenische Abteilug 71, 1956, p. 38; Caskey, J., "The Early Helladic Period in the Argolid", Hesperia 29, 1960, pp. 285-303.

(10) - O termo civilizaşẫo é tomado aqui no sentido francês, "civilisation" que corresponde a "cultures" da terminologia inglesa e germânica (p. 3, n. 12 e reflexốes sobre esse conceito à p. 519).

(11) - Hilde, G., L'Europe Préhistorique, Paris, 1962, p. 125; Milojcic, VI, "Die absolute Chronologie der Jungsteinzeit in Südosteuropa und die Ergebnisse der Radiocarbon (C 14) Methode", Jahrbuch des römisch-germanischen Zentralmuseums 14, 1967, pp. 9-37; Garasanin, M., "Zur Zeitbestimmung des Beginns der VincaKultur" Archaeologia Iugoslavica 1, 1954, pp. 1-6; "The Neolithic in Anatolia and the Balkans", Antiquity 35,1961, pp. 276-280; alguns arqueólogos romenos citados em Renfrew, C., Before Civilization, Londres, 1973, pp. 39-47 e 91-98.

(12) - Georgiev, G., "Kulturgruppen der Jungstein - und der Kupferzeit in der Ebene von Thrazien (Südbulgarien)", in Europe 1961, pp. 45-100; Deshayes, J., "Les fouilles de Dikili Tash et l'archéologie yougoslave", Zbornik Narodnog Mиzeja u Beogradu 6, 1970, pp. 21-41; Renfrew, C., "The Autonomy of the South- 
nominada alta, as civilizações neolíticas dos Bálcãs e da Europa são pois anteriores, em seu conjunto, àquela do Bronze Antigo egeano" (p. 10).

Para ordenar o estudo da estratigrafia, o Autor procedeu a uma pesquisa exaustiva dos sítios arqueológicos de uma vasta área geográfica compreendendo o conjunto das regiões egeanas no seu sentido mais amplo, (pp. 13-18) englobando, a leste, a parte ocidental da Anatólia; a oeste, estendendo-se até as ilhas jônicas e ao Epiro albanês; a noroeste, compreendendo a Macedônia grega — com a bacia de Korcë na Albânia, e a Macedônia iugoslava, prolongada pela região do Kosmet; ao norte, estende-se até os Bálcãs: cobre pois a Trácia grega e a bacia da Marica, na Bulgária; ao nordeste, o limite é a Trácia turca. Essa área (mapa 1) recebeu dez divisões regionais (mapa 2, pp. 16-17) agrupando os sítios arqueológicos onde foram descobertos vestígios da passagem do Neolítico Recente para o Bronze Antigo e nos quais foram feitas observações estratigráficas. Logicamente foi necessário um grande esforço de sistematização e de crítica; alguns critérios nortearam o Autor como a avaliação "da natureza e da precisão das técnicas de escavação, a extensão e a representatividade das zonas escavadas, a validez das extrapolações (...); os conhecimentos adquiridos desde a publicação das diferentes obras virão evidentemente reforçar e servir, em particular, para datar de modo mais preciso o que no passado só recebeu uma datação vaga ou aproximativa” (p. 10). Finalmente, algumas precauções foram sabiamente tomadas: seja eliminando alguns sítios que, na verdade, não revelaram uma verdadeira estratigrafia (o Heraion de Argos, Micenas, Korakou e Cheliotomylos, no Peloponeso), uma vez que "por certo não é suficiente que se tenha encontrado, em um mesmo sítio, cacos do Neolítico e do Bronze Antigo para que se possa falar de estratificação, sobretudo quando esses cacos não provém do mesmo ponto" ( $p$. 44); seja desvalorizando alguns dados estratigráficos mal interpretados, como por exemplo, ainda no Peloponeso, os referentes a Asea, Flionte, Gonia e Corinto, onde se pretendeu ver uma camada estratigráfica mixta que demonstrava uma lenta transição na passagem do Neolítico Recente ao Bronze Antigo. Um exame acurado dos dados disponíveis levou o Autor a constatar que "a estratificação primitiva foi completamente obliterada pelos remanejamentos posteriores: a camada mixta não é nada mais que uma camada alterada. Ademais, não se encontrou em nehum desses sítios a cerâmica mita que se podia esperar e — salvo em Corinto — nunca se encontrou cerâmica do Heládico Antigo I” (p. 58).

Do longo estudo da estratigrafia de um total de 87 sítios, ecompanhado de desenhos dos cortes estratigráficos, rigorosamente comentados jun-

East European Copper Age", Proceedings of the Prehistoric Society 35, 1969, pp. 12-47; "The Treering Calibration of Radiocarbon: an Archaeological Evaluation", id. 76, 1970, pp. 280-311; "Stagroi, radiocarbon and the prehistory of South-East Europe", Antiquity 45 ,1971, pp. 275-282; Before Civilization, Londres, 1973. 
tamente com o material arqueológico associado (pp. 18-109), R. Treuil obtém algumas conclusões (pp. 110-114), entre as quais, pela sua relevância, destacamos alguns pontos. O primeiro grande resultado é uma resposta à contemporaneidade ou não das civilizações do Neolítico Recente e do Bronze Antigo no mundo egeano. As observações estratigráficas confirmaram definitivamente que elas são distintas e sucessivas: na Macedônia e na Trácia os dados conseguidos recentemente são determinantes nesse sentido; em outras regiões e, principalmente no Peloponeso, o que se pensava tratarse de camadas mixtas eram apenas camadas remanejadas e nunca se pôde descrever o material de tipo intermediário que deveria, logicamente, testemunhar a existência de uma fase de transição.

A partir daí, foi possível delinear uma cronologia relativa das civilizações egeanas do Neolítico e do Bronze Antigo (fig. 30, p. 111) e, através do estudo do material cerâmico associado aos estratos, caracterizar essas civilizações. Tal caracterização demonstrou que o Bronze Antigo não pode ser definido como até então a partir de Tróia I, em vista de descobertas dos últimos anos indicando a existência de uma fase intermediária entre o Neolítco Recente e o período de Tróia $\mathbf{I}$. Basta lembrar a estratigrafia de Poliochni confirmando a presença de dois níveis do Bronze Antigo anteriores a Tróia I (pp. 18-20) (13); as estratigrafias de Sitagri e de Dikili Tash (Macedônia oriental) provaram que no início do Bronze Antigo havia uma fase anterior a Tróia I (pp. 94-99) (14.).

Uma outra ordem de resultados decorrentes do estudo estratigráfico refere-se à existência de seqüiências que apresentam uma repartição regional (mapa 3 e pp. 113-114). Nas regiões orientais do mar Egeu (com a exceção duvidosa de Embório), em Creta, no Peloponesco e na Grécia central, todas as seqüências estratigráficas estudadas caracterizam-se pelo fato de serem descontínuas, explicando que as aglomerações neolíticas foram abandonadas no fim do Neolítico Recente e não foram reocupadas a não ser em alguns casos e bem mais tarde, não antes do Bronze Antigo II; conclui-se, pois, que as primeiras aglomerações do Bronze Antigo nunca se instalaram sobre as ruínas de uma ocupação do Neolítico Recente. Outras seqüiências importantes são contínuas, como as observadas em alguns sítios da Tessália e do sul da Macedônia, na Macedônia central e oriental e, provavelmente, na Trácia meridional. Nessas regiōes verifica-se uma ocupação do Neolítico Recente e do Bronze Antigo I, havendo ainda, em alguns casos, um prolongamento no Bronze Antigo II.

(13) - Escavações italianas de Bernabó Brea: Poliochni. Città preistorica nell'isola di Lemmos. I. Roma, 1964.

(14) - Renfrew, C. "Sitagroi, radiocarbon and the prehistory of South-East Europe", Antiquity 45, 1971, pp. 275-282; Deshayes, J., "La séquence des cultures a Dikili-Tash", Actes du VIII.e Congrès I.S.P.P. II, pp. 492-496; "Dikili-Tash and the origins of the Troadic Culture, Archaeology 25, 1972, pp. 198-205. 
Essa constatação possível através do estudo da estratigrafia, revelando uma continuidade na ocupação de algumas regiões e uma descontinuidade em outras, levou R. Treuil, em suas conclusões gerais (pp. 515-516), a tentar explicar as causas dessa segunda seqüência, a descontinuidade, decorrente sem dúvida nenhuma de uma mudança no povoamento. O abandono das aglomerações neolíticas, seguido da fundação de novos povoamentos em lugares diferentes, conduziu o Autor à hipótese clássica de uma migração nessas regiões, apontando a Anatólia como origem possível dessa corrente. Qualquer tomada de posição mais definida a esse respeito, sobretudo no que concerne a caracterização dos grupos migratórios, se esbarra em inúmeras dificuldades, entre as quais, a pesquisa em antropologia física, cuja fragilidade, no que respeita essa área, é salientada com muita razão. Alguns indícios apontariam principalmente o deslocamento de aglomerações vindas do sudoeste da Anatólia, mas não existe nada que se possa realmente comprovar, havendo um só indício passível de algum significado nesse sentido; a referência à conhecida passagem de Tucídides (I, VIII, 1) é aqui plenamente justificável: "O único (indício) que em suma pode ter algum valor é na verdade o testemunho de Tucídides, segundo o qual os primeiros habitantes insulares eram cários em sua maioria, como o comprovam as sepulturas encontradas em Delos em 426, no momento da purificação da ilha" (p. 516).

As observações estratigráficas e a cronologia relativa que delas resultam foram confrontadas com as datações obtidas pelo métodos do carbono 14 (C 14) e pela termoluminescência (TL), a fim de provar a sua coerência e traduzí-la em termos de cronologia absoluta (pp. 115-140).

No que concerne o $\mathrm{C} 14$, o repertório de todas as datações obtidas para o Neolítico Recente, Bronze Antigo I e Bronze Antigo II (pp. 116-125) nas regiões egeanas e danubianas, num total de 187 resultados, oferece uma repartição estratigráfica muito desigual, havendo um número maior para o Neolítico Recente (113 datações) e bem menor para os outros períodos (20 datações apenas para o Bronze Antigo I e 54 para o Bronze Antigo II). Essa desigualdade refere-se também à repartição geográfica, sendo privilegiadas as regiōes da Macedônia, Sérbia e o Baixo-Danúbio para o Neolítico Recente (78 datações) enquanto o restante das regiões egeanas produziu somente 35 datações. Para o Bronze Antigo I e o Bronze Antigo II, as datações concentram-se sobretudo nas áreas do norte e centro da Grécia.

Apesar de um quadro bastante incompleto, além de algumas incertezas que levaram o Autor a eliminar 15 datações, foi possível um estudo dos mais esclarecedores a respeito do carbono 14 e a cronologia relativa (pp. 125-134) e, em seguida, do carbono 14 e a cronologia absoluta (pp. 134137). 
No que concerne às datações pela termoluminescência (TL), seus dados são mais limitados: dispomos de apenas duas datações para o Neolítico Recente e oito para o Bronze Antigo II e o Autor compara-as com os resultados obtidos pelo C14 (p. 138). Entretanto, a esse respeito, as conclusões são aproximativas, graças à imprecisão própria ao método da termoluminescência (p. 139).

Finalmente, esse substancioso estudo da estratigrafia e das datações conduz a algumas conclusões da maior relevância (pp. 139-140). Dois aspectos merecem destaque: o quadro cronológico obtido e a posição relativa do Neolítico europeu e do Bronze Antigo egeano.

O quadro cronológico resultante aponta para datas bastante elevadas: o Neolítico Recente começaria segundo as regiốes, entre 5200 e 4700 a.C.; o Bronze Antigo I, por volta de 4000 ou 3800 a.C.; o Bronze Antigo II, entre 3200 e 2800, terminando em 2400 a.C. aproximadamente. Essas datações não coincidem com a cronologia absoluta obtida pelo método comparativo, a não ser para o final do Bronze Antigo II; mas elas concordam com as observações estratigráficas (p. 140) confirmando a sucessão dos períodos NR-BAI-BA II e reforça, assim, a validez da cronologia relativa extraída dessas observações estratigráficas e resumidas na fig. 30 .

$\mathrm{O}$ segundo aspecto conclusivo, refere-se à anterioridade do Neolítico europeu com relação ao Bronze Antigo egeano. A civilização de VincaTurda não pode mais ser considerada contemporânea de Tróia I, separando-se desta através da duração de duas fases correspondentes ao Neolítico Recente (representado pelas civilizações de Vinca-Plocnik e de Gumelnita) e ao Bronze Antigo I. Assim sendo, deve-se colocar a civilização neolítica dos Bálcãs e da Europa central ao nível das civilizações neolíticas das regióes egeanas, com uma capacidade de evolução análoga e não inferior como se supunha até então.

A primeira parte desse livro, com o estudo sistemático da estratigrafia e das dataçỗes, acrescido dos novos resultados obtidos, serve de quadro para a pesquisa sobre as técnicas e a civilização nas páginas seguintes. A segunda parte, as técnicas (pp. 143-342), é uma contribuição muito original à arqueologia mediterrânica e é nela que se verifica a marcante e fundamental inspiração da obra de A. Leroi-Gourhan no tocante à classificaıção das técnicas quanto à sua função. Houve, certamente, mais de uma adaptação das propostas do prehistoriador francês, como principalmente no caso das habitações, cuja tipologia foi preciso criar na íntegra. Mas, em tudo, "o problema essencial estava ao nível da significação" (p. 144). Assim sendo, esse estudo das técnicas nos períodos do Neolítico Recente e do Bronzes Antigo não só preenche uma grande lacuna na bibliografia 
específica, pelo fato de nunca ter sido ainda abordado a não ser ocasionalmente, mas também abre caminho para pesquisas originais metodologicamente assentadas.

Para tanto, algumas definições foram esclarecidas, sobretudo no que concerne o próprio conceito de descrição, indispensável ao estudo das técnicas: "longe de se limitar a generalidades, (a definição) deve ser tão precisa quanto possível; porém não é um paradoxo dizer que de fato é precisamente $o$ alargamento das perspectivas que permite atingir esta precisão, multiplicando o número dos documentos e assegurando melhor sua inserção em um quadro mais amplo e mais sólido" (p. 143). Além da simples descrição, o estudo das técnicas deve permitir: "abortar questôes mais complexas e mais profundas. Deve de início servir para definir, com relação às civilizações contemporâneas, o nível técnico atingido por essas civilizações egeanas do Neolítico e do Bronze Antigo. Deve, também, ajudar a precisar seus diversos domínios culturais e perceber melhor, em conseqüência, seus traços originais. Deve, enfim, permitir retraçar as etapas da evolução técnica, indicando a natureza, a data e a importância das mudanças que puderam se produzir nos diferentes períodos" (p. 143).

Três capítulos se seguem, então, com desenvolvimentos mais ou menos longos ou substanciosos, dependendo da importância maior ou menor dos vestígios disponíveis. O cap. I refere-se às técnicas de aquisição (pp. 145-164), distinguindo a caça, a pesca, o combate, a gtterra; o trabalho da terra, com referências às técnicas agrícolas até então pouco conhecidas; as matérias-primas minerais, clescie a proveniência até o transporte, passando pela extração. As técnicas de fabricação são tratadas no cap II (pp. 165-239), de início em materiais como pedra (e outros materiais duros como osso, chifre, marfim e conchas) e madeira; os metais são estudados de modo mais pormenorizado em vista da importante questão referente à prática da metalurgia e seus inícios; as técnicas em argila merecem também substanciosa pesquisa; por fim, destacam-se as técnicas de fabricação das fibras vegetais, peles e têxteis e, encerrando este capítulo, os fluidos permitem um desenvolvimento curioso a partir dos dispositivos e recipientes que serviam para contê-los (no caso de fluidos como grãos, água, azeite, etc.), transportá-los e despejá-los, conduzindo assim a um estudo dos recipientes de argila quanto às suas formas e quanto à difusão dessas formas . O Autor detém-se, em seguida, no tratamento das técnicas de consumo (cap. III, pp. 241-340), passando por alimentação, vestuário e toalete, para explorar, com maiores recursos documentais, as técnicas de construção, os tipos de habitação, o mobiliário e a utilização do espaço, outra das contribuições significativas nessa obra tão rica e original.

Além da substância metodológica e documental, a parte referente ao estudo das técnicas conduz a alguns resultados que modificam sobrema- 
neira o que se conhecia até então sobre as civilizações egeanas do Neolítico Recente e do Bronze Antigo. Essas conclusões (pp. 341-342) apontam, por exemplo, o fato de o Bronze Antigo não marcar nehuma etapa importante da evolução no tocante às técnicas de aquisição e de fabricação, uma vez que elas remontam ao Paleolítico ou ao Mesolítico. Conclui-se, ainda, que um segundo grupo de técnicas - trabalho da terra, técnicas da madeira e da argila, técnicas de construção - são particulares ao início do Neolítico, sendo que apenas a cerâmica aparece um pouco mais tarde (final do Neolítico Antigo, enquanto o trabalho do torno surge no Bronze Antigo III - Bronze Médio I). Para os períodos seguintes, a unica técnica nova é a metalurgia, mas ela nasce no Neolítico Recente e não no Bronze Antigo. Desse modo, deve-se salientar a constatação muito significativa de que não se produziu nenhuma revolução técnica no início do Bronze Antigo, mas que houve uma "evolução contínua e marca$\mathrm{da}$, em diferentes momentos, por fenômenos sem elos aparentes uns com os outros" (p. 341). Um ponto que merece ainda assinalar nessas conclusões é a multiplicidade dos domínios culturais das regiões egeanas, de modo a relacionar certas técnicas, ora com o Oriente Próximo (como no caso das construções), ora com a Europa (como no caso da tecelagem). Multiplicidade cultural e diversidade das áreas de difusão decorrem da observação atenta da distribuição espacial dessas técnicas, sendo esta a derradeira e não menos importante conseqüência dessa longa pesquisa sobre as técnicas, permitindo situar, por exemplo, um particularismo nas técnicas da caça próprio à ilha de Creta, e, nas técnicas de construção, sobressaindo-se as regiōes da Tessália e da Macedônia.

Não menos originais e plenos de ensinamentos são os capítulos reunidos na terceira parte denominada os homens ( $\mathrm{pp}$. 345-514). Começando com o estudo do povoamento, que abrange a demografia e o habitat (pp. 347-373), desenvolve em seguida um sugestivo capítulo dedicado à economia e à sociedade (cap. II, pp. 375-402), onde se destacam as considerações a propósito da agricultura e da coleta, como também a respeito do pastoreiro, da caça, da pesca, sem esquecer a problemática das trocas e a caracterização da sociedade. No que concerne a domesticação das plantas e dos animais, vale ressaltar algumas reservas e críticas ao estado da questão que situa no Oriente Próximo os seus inícios e daí se propaga em direção à Europa, ficando para as regiões egeanas o papel de intermediárias. Num e noutro caso, a história da arqueologia revelou dificuldades e desequilíbrios nas pesquisas, orientadas de modo privilegiado para o Oriente Próximo, em detrimento das áreas egeanas e européias, resultando assim um quadro bastante incompleto de informações sobre o assunto.

Com a denominação os costumes, tema do cap. III (pp. 403-460), R. Treuil engloba dois aspectos normalmente dissociados na bibliografia: maquetes e figurinhas de terracota, práticas funerárias - agrupamento esse 
que reflete, desde o início, as interpretações apresentadas em seguida, retirando desses costumes qualquer significado ao nível da religião, uma vez que essa é tratada separadamente no capítulo seguinte.

Referindo-se às figurinhas femininas antropomorfas, universalmente interpretadas como representações da Deusa-Mãe, venerada pelas populações prehistóricas, admite que nos períodos históricos elas tenham realmente tido essa significação, principalmente na Mesopotâmia, na Anatólia e na Grécia, mas no caso dos tempos muito recuados o valor religioso dessas figurinhas deve ser questionado. As primeiras dúvidas a respeito aparecem na obra de Nilsson (15) indicando "que as figurinhas eram passíveis de vários tipos de interpretação e que sua função religiosa nunca havia sido demonstrada" (p. 416). Makarenko (16), por outro lado, "observa que sua densidade era tal que a interpretação religiosa só podia levar à criação de um extenso panteão" (p. 416). Finalmente, Ucko (17) demonstrou "que essa interpretação, no caso das figurinhas neolíticas da Grécia e dos Bálcãs, não podia se suster" (cf. p. 417), conduzindo então R. Tretil a um cuidadoso estudo do material, retomando o conjunto das maquetes e das figurinhas (pp. 418-428), com base em dados etnográficos, arqueológicos e históricos. Sua constatação, de que se tratam de brinquedos de crianças, resulta de uma argumentação mais convincente, ainda que não comprovada inteiramente, como o Autor reconhece à p. 421: "Até aqui, entretanto, apesar de tantas convergências, nenhuma prova formal pôde ser fornecida, afora o caso particular das inúmeras figurinhas articuladas (fig. 125) encontradas em Jasatepe nos níveis do Neolítico Médio. Resta, pois, para o futuro, buscar os indícios suscetíveis de permitir uma demonstração."

No tocante às práticas funerárias, um grande esforço de síntese é apresentado (pp. 424-460) através do Neolítico acerâmico, antigo, médio e recente e por todo o Bronze Antigo, levando a um estudo crítico sobre a evolução histórica e a interpretação (pp. 451-460) dos diversos modos de enterramento e afastando qualquer significação a nível das crenças no mundo do além (p. 505). Mas, por outro lado, suas interpretações abrem caminho para mais de uma reflexão sobre os costumes funerários ficando bem nítida a riqueza e o potencial disponível para pesquisas que visem uma melhor compreensão do mundo dos vivos: "(...) é certo que os objetos - adornos e mobiliário - depositados nas sepulturas podem refletir,

(15) - Nilson, M. P. The minoan-mycenaen religion and its survival in Greek religion, 1a ed. Lund, 1927, pp. 248-250; $2^{\text {a }}$ ed. 1950, pp. 290-292.

(16) - Makarenko, N., "Sculpture de la civilisation Trypillienne en Ukraine". Jahrbuch für prähistoriche und ethnographische kunst, 1927, pp. 119-130.

(17) - Ucko, P. "The Interpretation of Prehistoric Anthropomorphic Figuri nes", Journal of the Royal Anthropological Institute 92, 1962, pp. 38-54; Anthropo. morphic Figurines of Predynastic Egypt and Neolithic Crete, Londres, 1968. 
pelo seu número e natureza, desigualdades de ordem social. Mesmo que uma parte deles possam ter desaparecido, mesmo se não percebemos, entre as razões possíveis de sua presença, apenas aqueles mais simples e mais evidentes, pudemos já sublinhar o contraste que existe entre a pobreza da maioria das sepulturas e a riqueza de uma minoria delas e, a partir daí, esboçar alguns traços das sociedades egeanas. Mas fica, para o futuro, prosseguir a pesquisa nessa via, que é provavelmente uma das mais fecundas, e estudar novas sepulturas prestando a maior atenção às relações que unem a arquitetura funerária, e sobretudo o mobiliário, à idade e ao sexo dos mortos. Desse modo, deveria ser possível precisar e justificar essas noções de pobreza e de riqueza que empregamos instintivamente; captar, graças à elaboração de uma tipologia dos mobiliários funerários, a existência e a definição de diferentes tipos de status sociais; e avaliar, enfim, a natureza e a amplitude das variações introduzidas, nesse domínio pela idade e pelo sexo" (pp. 459-460).

$\mathrm{O}$ livro de R. Treuil se encerra com um capítulo sobre a arte e o pensamento simbólico (cap. IV, pp. 461-511), no qual são estudados os sistemas decorativos, os adornos e as estatuetas, a religião, os símbolos e a escrita. Através de desenhos que ilustram os vários motivos decorativos, deduz-se a grande complexidade e riqueza do sistema decorativo próprio do Neolítico Recente, em oposição à rarefação e unidade dos estilos do Bronze Antigo. Por outro lado, é o estudo dos adornos que leva o Atutor a abordar a questão das estatuetas de pedra, sobretudo de mármore, figuras antropomórficas, de função desconhecida, mais numerosas no Bronze Antigo que no Neolítico Recente, e características da Anatólia ocidental, da região nordeste do Egeu, das Cíclades, Creta e Grécia central.

A comparação com as figurinhas de terracota já mencionadas se impõe, sem dúvida, mas elas pertencem a universos diferentes. A série de pingentes de materiais duros (pedra, osso), representando figuras antropomórficas, parece ser de interpretação mais evidente e, aproximada a exemplares com a forma de mão, pé, falo, levaria a supor uma função em práticas mágicas. Para as estatuetas aqui tratadas, a interpretação religiosa também foi proposta, principalmente aos exemplares femininos de pedra, que seriam representações da Deusa-Mãe; ou teriam significado funerário, posto que alguns desses objetos foram encontrados em sepulturas. Mas todas essas possíveis funções vão de encontro a inúmeras objeções, apresentadas de maneira pertinente pelo Autor. "Fica, pois, para o futuro, reunir as observações que permitiriam ir mais longe, em particular aquelas que concernem o contexto no qual esses objetos aparecem. Escavar casas de. veria dar a ocasião de determinar seu lugar habitual e verificar sua posição exata. Escavar sepulturas deveria fornecer o meio de precisar as relações que podem ligar as estatuetas às figurinhas, à natureza e à riqueza do mobiliário funerário e, enfim, ao sexo e à idade dos mortos" (p. 504). 
A religião é tratada em duas páginas (pp. 505-506) muito críticas quanto aos objetos até então interpretados como tendo valor religioso e quanto a suas associações no Neolítico e no Bronze Antigo. A questão dos locais de culto, como os santuários, é mais do que duvidosa e o Autor, citando Lamb e Branigan (18), admite que somente a partir de Tróia II e do Bronze Médio se reconhece na Anatólia e em Creta santuários clara-' mente identificáveis.

A observação atenta dos vestígios arqueológicos disponíveis, sua interpretação rigorosamente isenta de influência devidas a fatos religiosos próprios dos períodos mais recentes, conduzem $\mathrm{R}$. Treuil à conclusão de que as religiões praticadas no Neolítico e no Bronze Antigo são totalmente desconhecidas. Sua conclusão não é negativa mas dubitativa: "Que nós às vezes nos enganemos ao propor uma interpretação religiosa a objetos ou fatos que nada têm a ver com a religião, que forcemos o silêncio dos que não falam ou que transponhamos para o passado noções aplicáveis às épocas melhor conhecidas, nada disso implica que o homem egeano do Neolítico e do Bronze Antigo não tenha tido sua religião ou suas religióes: isso mostra somente que nós não a conhecemos. Mas é provável que dentre os documentos que vemos, e mais ainda dentre aqueles que não percebemos, haja alguns que permitirão um dia lançar as bases de um estudo sólido deste fenômeno capital" (p. 506).

Os últimos aspectos culturais desse capítulo referem-se aos símbolos e à escrita (pp. 506-511) e, através da apresentação dos tipos de notação simbólica, delineiam-se as primeiras tentativas de comunicação e registro nos períodos Neolíticos e Bronze Antigo. 'Essa questão é das mais relevantes para a história da civilização e a documentação estudada nesse livro é plenamente adequada às afirmações conclusivas do Autor. Basta atentar para o surgimento em Creta, no Bronze Médio, de um primeiro sistema de escrita, o sistema pictográfico, que pressupõe a utilização provável, nos períodos anteriores, de algum tipo de notação simbólica.

Os exemplos do Neolítico são de difícil interpretação quanto a uma função precisa, entretanto não deixam de ser etapas significativas na busca de uma expressão gráfica: nos Bálcãs e na Tessália são enigmáticas algumas decorações incisas em vasos, discos de argila e pesos de tear, bem como traços incisos (feitos após o cozimento) em tabletes de argila. Por outro lado, durante todo o período Neolítico no Oriente Próximo, na Anatólia, nas regiões setentrionais do Egeu e nos Bálcãs, existiu uma notação

(18) - Lamb, W., "Some Early Anatolian Srines", Anatolian Studies 6, 1956, pp. 87-88 Branigan, K. "The genesis of the Household Goddess", Studi Micenei e Egeo-Anatolici 8, 1969, pp. 28-38. 
simbólica em terracota ou pedra, convencionalmente denominada selo ou "pintadera", que parece ter servido para a aplicação de pinturas corporais.

No Bronze Antigo, ainda que indecifráveis, subsistiram duas séries de notações simbólicas de significado mais evidente: sinais que aparecem em vasos de argila, executados antes do cozimento, são interpretados como marcas de oleiro; ademais, surgem nesse período, em argila, metal, marfim e sobretudo pedra, os selos conhecidos de modo direto ou através de suas impressões (como, por exemplo, as que se vêem na fig. 267 - impressões de selos de Lerna do Bronze Antigo II).

A grande lição das duas últimas partes da obra referentes às técnicas e aos homens, as quais, na verdade, exploram todos os importantes fatos de civilização perceptíveis nas regiões egeanas durante o Neolítico e o Bronze Antigo, se depreende a partir da contribuição maior de um e de outro desses períodos (pp. $512-514 ; 515-519$ ). Se por um lado, coube ao Neolítico o grande papel representado pela invenção de técnicas, na organização da sociedade destaca-se o Bronze Antigo: "No domínio da organização social, política e econômica, contudo, há no Bronze Antigo uma convergência que leva as regiões mericlionais do Egeu, e apenas elas, a uma evolução comparável à que se dá no Oriente Próximo. O terreno é preparado, talvez, pela aquisição antes e durante a época neolítica, de uma gama de técnicas análogas às técnicas dessas regiões e pela elaboração de um modo de subsistência comparável. Mas aparecem fatos novos, que por serem dispersos e às vezes ambíguos, não têm menos valor de indícios. São os inícios da cultura da vinha e da oliveira, isto é, da policultura mediterrânica; o aparecimento de artesãos no verdadeiro sentido da palavra; a acentuação das desigualdades econômicas, revelada pelos mobiliários funerários; a concentração provável das capacidades de estocagem e de redistributição 'de gêneros; enfim, a reunião da força econômica ao poder político. Acrescentam-se a isso os progressos dos sistemas de notação simbólica, que tornam possível a organização da economia. Todos esses traços vão conduzir ou permitir — o próprio mecanismo nos escapa - a instalação do sistema palacial. Com efeito, no Bronze Médio, Creta é caracterizada pela existência de palácios, de cidades e de um sistema de escrita; os palácios integram-se ao tecido urbano e utilizam a escrita, acelerando muito provavelmente sua difusão. O Bronze Antigo, que precede esse estágio, reveste-se, pois, no plano da organização da sociedade, de uma importância que não teve em outros planos, em particular no das técnicas" (p. 513).

Mesmo que o livro de $\mathrm{R}$. Treuil não levasse a outras conclusões ou reflexões aprofundadas a respeito da vasta documentação material de que dispomos para o Neolítico e o Bronze Antigo - o que, aliás, está bem longe 
de ser verdadeiro, tal é a riqueza e a variedade de temas cujo tratamento foi inteiramente reformulado por uma metodologia segura - só os resultados que levam a caracterizar o Bronze Antigo como uma "fase preparatória" ao estabelecimento do sistema palacial em Creta dá a justa medida da valiosa contribuição dessa tese, plena de conhecimentos arqueológicos, históricos e etnológicos, assentada num rigoroso esforço crítico e altamente estimulante, a ponto de sugerir, a cada passo, inúmeras e preciosas perspectivas de pesquisa. 